\title{
Marine cements of the Dengying Formation from South China reveal the terminal Ediacaran ocean anoxia
}

\author{
JINGBIN WANG ${ }^{1,2}$, ZHILIANG HE ${ }^{1,2}$, DONGYA ZHU ${ }^{2}$
}

${ }^{1}$ China University of Geosciences Beijing, Beijing 100083, China, No. 29 Xueyuan Road, Beijing, 100083;

${ }^{2}$ Petroleum Exploration and Production Research Institute of SINOPEC;

wjb_cugb@outlook.com

Marine carbonate archives are potentially ideal targets to understand ocean chemistry and redox state. A critical problem in using carbonate archives to decipher Precambrian seawater chemistry is the apparent lack of primary marine precipitates. Although a redox-stratified oceanic model has been proposed, the terminal Ediacaran ocean redox state for the shallow water in South China is not well understood.

We reexamined the Dengying Formation dolomite that were deposited in a shallow reef-shoal setting, and provided multiple proxies to rebuilt ocean redox states. Firstly, abundant primary fibrous marine dolomite cements are recognized, like the Beck Spring Dolomite and Balcanoona Reef. Petrographic, geochemical and crystallographic evidence show that they have length slow character and well-preserved textural and luminescent growth zonation, indicating that they were directly precipitated from the largely unmodified seawater during a syn-sedimentary stage and could record the redox state of seawater. Further, no correlations between carbon and oxygen isotopes and other diagenetic proxies imply that marine cements are robust against diagenesis or contamination, retaining original seawater chemistry. Thus, the relatively low levels of chalcophile elements $(\mathrm{Co}, \mathrm{Cu}, \mathrm{Pb}$ and $\mathrm{Zn})$, $\mathrm{V}, \mathrm{Cr}$ and iron suggest non-ferruginous, euxinic (both anoxic and sulphidic) conditions when compared to other marine cements from the Balcanoona reef under ferruginous anoxic Cryogenian oceans. More, the primary marine cements have apparent convex shale-normalized REY profiles with negligible Ce anomalies, different from those of the pore-filling crystalline dolomite, implying that anoxic conditions prevailed during the deposition of Dengying Formation. Positive Eu anomaly can also be a compelling evidence for extensive marine anoxic water, since excess Eu can be largely preserved under anoxic conditions. Such anoxic signatures for the terminal Ediacaran ocean are consistent with the results of U-, Cr- and $\mathrm{S}_{\text {pyrite }}$ isotopes.

More importantly, it is worth highlighting that anoxic (even euxinic) seawater conditions, associated with high $\mathrm{Mg} / \mathrm{Ca}$ ratios, low dissolved sulphate, high alkalinity and elevated microbial activity together constitute the unusual Ediacaran 'aragonitedolomite sea' micro-environments for dolomite precipitations, which helps to understand the widespread Precambrian dolomite distributions worldwide. 